\title{
Characterization and importance of pig breeds in the pork industry of the zone of Bobo-Dioulasso (Burkina Faso, West Africa)
}

\author{
T. KIENDREBEOGO ${ }^{1 *}$, Y. MOPATE LOGTENE ${ }^{2}$, S. R. KONDOMBO ${ }^{3}$ and \\ C. Y.KABORE-ZOUNGRANA ${ }^{4}$
}

${ }^{1}$ Institute of the Environment and the Agricultural Researches (INEAR), Department of Animal Productions (AP)/Monogastric Program, Station of Farakobâ, 01 BP 910 Bobo-Dioulasso, Burkina Faso 01.

${ }^{2}$ Laboratory of Zootechnical and Veterinary Researchs (LZVR) of Farcha, B.P. 433, N'Djamena, Tchad, Associated Researcher of the Laboratory of Study on the Natural Resources of and the Environment Sciences (LSNRES) of Polytechnic University of Bobo-Dioulasso (PUB).

${ }^{3}$ Institute of the Environment and the Agricultural Researches (INEAR), Department of Animal Productions (AP) /Monogastric Program, Station of Kambouinsé.

${ }^{4}$ Laboratory of Study on the Natural Resources of and the Environment Sciences(LSNRES) of Polytechnic University of Bobo-Dioulasso(PUB), 01B.P.1091 Bobo-Dioulasso 01 Burkina Faso.

*Corresponding author; E-mail: timbilfou@gmail.com, Tél. (+226)70223003 /(+226)20962946.

\begin{abstract}
This study aimed at characterizing and evaluating the importance of pig breeds in the pork industry of the zone of Bobo-Dioulasso (Burkina Faso, West Africa). Some data of a diagnosis of the pig breeding systems (2003) and other data of a survey about the pig meat supply (2005), were analyzed. The stocktaking shows that the local or indigenous breed is $61 \%$, the Korhogo breed $34 \%$, the Mongrel breed is $4.52 \%$ and the Large White breed $0.48 \%$. In the intensive system, only Korhogo breed is raised. In the semi-intensive the Korhogo, followed by the local breed are more raised. In the extensive system, the Local breed, followed by the Korhogo, is more raised. The Korhogo breed was more used in the exchanges of boars in all the systems. Butchers and pork butchers prefer local breed (50\%) as well as improved breeds (Korhogo breed, Large White breed and Mongrel breed). Cooks with oven prefer local breed (64.29\%) more than improved breeds (35.71\%). The uncontrolled exchanges and hazardous crossing between pig's breeds constitute some risks of either the extinction of the local breed, or the problem of consanguinity or even the threat for genetic diversity. It is necessary to carry out a genetic characterization of these breeds in order to organize better a more productive and durable management of pig breeds and breeding in the zone of Bobo-Dioulasso.
\end{abstract}

(c) 2012 International Formulae Group. All rights reserved.

Key words: Pork industry, pig breed, characterization, systems of breeding, Bobo-Dioulasso.

\section{INTRODUCTION}

In Burkina Faso, breeding constitutes the second pillar of the economy. This activity contributes approximately $12 \%$ to the formation of Gross domestic product (GDP), constitutes $30 \%$ of the export earnings and occupies more than $80 \%$ of the population needing. The pig breeding is in constant increase. For instance, the stocktaking of 2003 showed that there were 1886234 heads 
against initially awaited 760000 heads) (MEF and MRA, 2004), so be it an increase of $18.6 \%$ between 1993 and 2003. The promotion and the improvement of the pig breeding productivity constitute some strategic options with the view to making the meat be quickly available in some affordable costs to the population. Among the factors being able to contribute effectively to this development, the breed is of paramount importance. Denmark for example, after the food factor, was based on the creation of a national pig breed with high performances, a breed called the Danish landrace, used in crossings. This strategy allowed this country to develop the porcine production and to increase at the same time the exported pork shares of $60 \%$ in 1950 to approximately $78 \%$ nowadays (CIRAD, 2009). The same author indicates that the contribution of China to the technological development of the pig industry was especially through its specific genetic inheritance, which places it as the greatest zone of pig production of the world $(43 \%$ in 1994). Lebret et al. (2008) concluded, following a study, that the breed could influence the growth and the composition of the meat. They report that the pig of Basque's breed seems to be lower weighted than the Large White breed when still alive. Cut down, the former caught up with weight difference on the level of the carcasses. Moreover, the authors recognize that the differences observed, in terms of meat quality, can be, partially explained by the breed (Holnes, 1994). Several African countries imported breeds of pig known as "improved breeds" with the aim to a genetic improvement. This is justified by the fact that, in some countries of West Africa (Côte-d'Ivoire, Nigeria) and some of Central Africa (Cameroon) the qualified animals as improved breeds represent between 10 and $20 \%$ of the pig population.These animals, seldom of pure breed, are the product of multiple crossings between the local (indigenous) breed and the imported breeds, which are more productive (Drabo, 2007). The pig breeding is a significant activity in the urban and suburban area of Bobo-Dioulasso. According to MED and MRA (2004) the Hauts-Bassins region (12.6\% of total pigs), whose Bobo-Dioulasso is the principal city, is classified the $4^{\text {th }}$ on 13 administrative regions which constitute Burkina Faso. The urban and suburban pig breedings of Bobo-Dioulasso are in an intensification dynamics but remain largely extensive (MED and MRA, 2004). The region of the Hauts-Bassins, whose Bobo-Dioulasso is the main city, is classified the fourth of 13 regions with $12.6 \%$ the country's pigs total numbers. An intensification dynamics is applied on the pig breeding of the urban and the peripheral areas. Seeking for a greater productivity, the use of the improved pig breeds is frequent. This implies an uncontrolled use of pigs'breeds in the zone. These practices could not only threaten genetic diversity but also produce some disappointing performance of production and reproduction (MED and MRA, 2004). In this context, the knowledge of pig breeds, which take part in the production, becomes necessary for a better organization of a sustainable pig production. However, in the zone of BoboDioulasso, no specific study interests itself neither to the stocktaking of pig breeds, nor the phenotypical and genetic characterization of pigs' breeds. The present study wants to make an inventory and to characterize the phenotypical pig breeds according to the literature, in order to contribute to a better management of genetic resources of the pig production

\section{MATERIALS AND METHODS \\ Zone of the study}

The study was carried out in and around the town of Bobo-Dioulasso (489967 habitants) (MEF, 2008). Bobo-Dioulasso is located at $365 \mathrm{~km}$ from Ouagadougou, the capital of Burkina Faso, and in the Sudanese climate. The annual precipitations lie between 800 and $1200 \mathrm{~mm}$. Generally, the low ambient temperatures lie between $23{ }^{\circ} \mathrm{C}$ and $30{ }^{\circ} \mathrm{C}$. Burkina Faso is made up of 13 administrative 
regions among which the area of the HautBassins, whose Bobo-Dioulasso is the principal city. This region counts 212813 heads of pigs. This accounts for $12.26 \%$ of national total numbers (1 889234 heads of pigs) (MED and MRA, 2004). The HautBassin region is classified the $4^{\text {th }}$ on the 13 regions after the Western Center (367 617 heads), the Western South (251 176 heads) and the Boucle du Mouhoun (217 758 heads).

\section{Data gathering}

The data of two surveys were used for the study. The first one (2003) was done near 623 pig breedings of the urban and suburban zone of Bobo-Dioulasso and the second one (2005) was done to pig meat and/or pig meat products sellers and transformers. The first survey made possible the characterization of the pig breeding systems through the establishment of a typology (Kiendrébéogo et al., 2008) (Table 1). Based on this typology, an inventory and an evaluation of the importance of pig breeds raised in the zone were carried out.

\section{Data analysis}

The Data were analyzed using software SPSS® 11.0 version and XLSTAT 2009 version. The calculation of frequencies method was used to determine the rate of each pig breed in each system. The Pig breeds productivity was evaluated through the calculation of some parameters of reproduction and production (weight of the sold adult pigs). The weight of pigs was used in the analysis of variance (ANOVA) according to Fisher's (LSD) test at $\mathrm{p}<5 \%$ as the significant level to appreciate the influence of breeds, the breeding systems and their interactions on the formation of the average weights of the adult pigs which would be sold. Finally, an analysis of frequency was made to appreciate the breeds of pigs preferred by each type of the pig meat and its products actors (transformers and sellers) in Bobo-Dioulasso.

\section{RESULTS}

The Pig breeds and its importance according to the breeding systems in the urban and suburban areas of BoboDioulasso

Three breeds of pigs and mongrel pigs were noticed in the urban and suburban areas of Bobo-Dioulasso: the local or Indigenous breed (Figures 1 and 2), the Korhogo breed (Figure 3), the Large White or Yorkshire breed (Figure 4) and the Mongrel pigs. The Results (Figure 5) show the average distribution of pigs according to the different breeding systems and pigs' breeds. The Local breed $(61 \%)$, was globally more represented, followed by the Korhogo (34\%) breed. According to the breeding systems, the Korhogo breed was more represented in intensive system (99.63\%). In the semiintensive breeding system, the Korhogo breed $(70.64 \%)$ and the Indigenous breed $(22.42 \%)$ were more represented. In the extensive breeding system, the Indigenous $(61.35 \%)$ and the Korhogo $(34.07 \%)$ breeds were more represented. The Large White was present with $0.37 \%, 1.92 \%$ and $0.23 \%$ respectively in intensive, semi-intensive and extensive systems. The Mongrel breed, very little represented in the semi-intensive breeding system and in the extensive breeding systems. In the opposite this breed was absent in the intensive system.

\section{Parameters of reproduction according to the pigs' breeds and to the breeding systems}

The results of Table 2 show the principal parameters of reproduction of pig's breeds. They show significant abortions of the Korhogo breed in the semi-intensive system. They also show significant mortalities before weaning ( 2 to 3 months) for all breeds in the semi-intensive and extensive systems. The mongrel breed showed high death rates at the adulthood in the semi-intensive system compared to the extensive one. 
The Impact of pig breeds on the weight of pigs sold in the herds with several breeds

The sale of all pig's breed took place with $11 \pm 2$ months of age to an average weight of $92 \pm 35 \mathrm{~kg}$ in the intensive system, $14 \pm 2$ months and $97 \pm 42 \mathrm{~kg}$ in the semi-intensive and $11 \pm 5$ months with $60 \pm 33 \mathrm{~kg}$ in the extensive system. The average weights where very significantly different $(\mathrm{p}<0.05)$ between breeding systems. The Table 4 presents the descriptive statistics of the variables of correlation analysis. There was a significant negative correlation $(\mathrm{P}<0.05)$ between the WeightSP and NLocB, and positive correlation between WeightSP and NKrgB and NLwB.

The results of the variance analysis (Tables 4) show that the null hypothesis (H0) was dismissed. There was an effect of the presence and the number of the breed in the herd on the weight average of the adult pigs sold $(\mathrm{P}<0.05)$.

Implication of the breeds of pig in the exchanges of boars for coupling

No loan of boar was carried out in $100 \%, 87.57 \%$ and $87.10 \%$ of the cases respectively in the system intensive $(n=5)$, extensive $(n=587)$ and semi intensive $(n=31)$. There were not loans in $100 \%, 77.4 \%$ and $92.84 \%$ of the cases respectively in the system intensive, semi-intensive and extensive. The results in Figure 6 show that the Korhogo breed was more used than the local one in the semi-intensive system than in the extensive system.

Breeds of pig preferred by the tradesmen and pork transformers in Bobo-Dioulasso

The actors of the marketing of the meat and derivative products of pork (35) do not have preferably between pigs' breeds $(48.57 \%)$ as grill-room owners with oven (PF) $(94.12 \%)$ and restaurant owners $(5.88 \%)$. Other actors $(51.43 \%)$ have a preference between the local breed $(61.11 \%$ of them) and the improved breeds (38.89\%). The butchers and the pork sellers have chosen between the local breed and the improved breeds with equal rate $(50 \%)$. The PF chose the local breed $(64.29 \%)$ and the improved breeds $(35.71 \%)$.

Table 1: Principal elements characteristic of the systems of breedings of the zone.

\begin{tabular}{lccc}
\hline Characteristics variables & \multicolumn{3}{c}{ Breeding Systems } \\
\cline { 2 - 4 } & Intensive & $\begin{array}{c}\text { Semi- } \\
\text { Intensive }\end{array}$ & Extensive \\
\hline Frequency of the breeding (\%) & 0,80 & 4,98 & 94,22 \\
Place of installation & Suburban & Suburban & Rural \\
Agricultural Field (ha) & 1 & 2 & 4 \\
Average Investment for housing and Equipment (FCFA) & 4631000 & 1194415 & 115687 \\
Herd of pigs (Head) & 107 & 46 & 13 \\
Sows (Head) & 8 & 6 & 2 \\
Improved breeds (Head) & 107 & 36 & 4 \\
Paid employees (n) & 1 & 1 & 0 \\
Guarding & PC* & PC & PAC** \\
Food and health expenditure /an & 975020 & 706021 & 121595 \\
Practical of rationing & yes & Yes & Not \\
Practical of the Artificial insemination & Yes & not & not \\
\hline
\end{tabular}


Table 2: Parameters of reproduction of the porcine breed according to breeding systems.

\begin{tabular}{|c|c|c|c|c|c|c|c|c|}
\hline \multirow{2}{*}{ Pig breeds } & \multirow{2}{*}{ Systems } & \multicolumn{2}{|c|}{ TP (pilets) } & \multicolumn{2}{|c|}{ IIMB (mois) } & \multirow{2}{*}{$\begin{array}{c}\text { AVORT } \\
(\%) \\
\end{array}$} & \multirow{2}{*}{$\operatorname{MAS}(\%)$} & \multirow{2}{*}{$\operatorname{MPS}(\%)$} \\
\hline & & $\mathrm{n}$ & mean & $\mathrm{n}$ & mean & & & \\
\hline \multirow{3}{*}{ Korhogo } & Intensive & 5 & $10 \pm 2^{\mathrm{a}}$ & 5 & $6^{\mathrm{a}}$ & 0 & 3 & 0 \\
\hline & Semi-intensive & 21 & $10 \pm 2^{b}$ & 18 & $6 \pm 1^{b}$ & 14 & 25 & 4 \\
\hline & Extensive & 92 & $8 \pm 2^{c}$ & 80 & $6 \pm 1^{b}$ & 2 & 18 & 4 \\
\hline \multirow[t]{2}{*}{ Indigenous } & Semi intensive & 6 & $6 \pm 1^{\mathrm{a}}$ & 6 & $6 \pm 1^{a}$ & 6 & 6 & 6 \\
\hline & Extensive & 423 & $7 \pm 2^{\mathrm{a}}$ & 401 & $7 \pm 1^{\mathrm{a}}$ & 6 & 18 & 2 \\
\hline \multirow[t]{2}{*}{ Mongrel breed } & Semi-intensive & 3 & $10 \pm 3^{\mathrm{a}}$ & 3 & $6^{\mathrm{a}}$ & 0 & 25 & 20 \\
\hline & Extensive & 45 & $10 \pm 2^{\mathrm{a}}$ & 43 & $7^{\mathrm{a}}$ & 0 & 13 & 0 \\
\hline \multirow[t]{2}{*}{ Large White } & intensive & 2 & $10 \pm 2^{\mathrm{a}}$ & 2 & $6 \pm 1^{a}$ & 7 & 17 & 0 \\
\hline & Semi-intensive & 3 & $9 \pm 2^{\mathrm{a}}$ & 2 & $7 \pm 2^{\mathrm{a}}$ & 3 & 15 & 2 \\
\hline
\end{tabular}

The means with different letters are significantly different $(\mathrm{p}<5 \%)$. TP= Size of the ranges; IIMB $=$ Interval between low setting; AVORT= Abortions; MAS= Mortality before weaning; MPS= Mortalities post weaning.

Table 3: Descriptive characteristics of the variables of analysis.

\begin{tabular}{lcccccccc}
\hline Variable & \multicolumn{3}{c}{ Descriptives statistics } & \multicolumn{5}{c}{ Correlations } \\
\cline { 2 - 8 } & $\mathbf{N}$ & Moyenne & Ecart-type & WeightSP & NLocB & NKrgB & NMogB & NLwB \\
\hline WeightSP & 403 & 62,733 & 35,056 & 1 & $-0,132^{*}$ & $0,286^{*}$ & 0,052 & $0,157^{*}$ \\
NLocB & 623 & 9,35 & 10,865 & $-0,132^{*}$ & 1 & $-0,215^{*}$ & $-0,119^{*}$ & $-0,061$ \\
NKrgB & 623 & 5,193 & 17,216 & $0,286^{*}$ & $-0,215^{*}$ & 1 & $-0,031$ & 0,004 \\
NMogB & 623 & 0,623 & 4,074 & 0,052 & $-0,119^{*}$ & $-0,031$ & 1 & 0,003 \\
NLwB & 623 & 0,074 & 1,035 & $0,157^{*}$ & $-0,061$ & 0,004 & 0,003 & 1 \\
\hline The values in fat with * are significantly different of 0 at a level of significance of alpha=0.05; WeightSP= Weight of the \\
sold pigs; NlocB= Number of pigs of Local (Indigenous) breed in the herd; NKrgB= Number of pigs of Korhogo breed in \\
the herd;NLwB= Number of pigs of Large white breed in the herd
\end{tabular}

Table 4: Effects of the presence and the number of the breed of pig in the herd on the weight of the pigs to the sale.

\begin{tabular}{lccccc}
\hline Source & Valeur & Ecart-type & $\mathbf{t}$ & $\mathbf{P r}>|\mathbf{t}|$ & Signification \\
\hline NLocB & 0,105 & 0,049 & 2,157 & 0,032 & $* * *$ \\
NKrgB & 0,144 & 0,049 & 2,926 & 0,004 & $* * *$ \\
NMogB & 0,020 & 0,064 & 0,314 & 0,754 & $* * *$ \\
NLwB & $-0,413$ & 0,073 & $-5,615$ & $<0,0001$ & $*$ \\
Breeds present-Krg & 0,090 & 0,149 & 0,600 & 0,549 & $*$ \\
Breeds present-Krg+Lw & 0,134 & 0,056 & 2,397 & 0,017 & $*$ \\
Breeds present-Loc & $-0,265$ & 0,164 & $-1,614$ & 0,107 & $*, 428$ \\
Breeds present-Loc +Krg & $-0,069$ & 0,087 & $-0,793$ & 0,428 \\
Breeds present-Loc+Mgl & $-0,028$ & 0,042 & $-0,668$ & 0,504 & \\
Breeds present-Lw & 0,673 & 0,072 & 9,401 & $<0,0001$ & \\
Breeds present-Mgl & 0,000 & 0,000 & & \\
\hline & $*$ Significant and ***high significant incidence (p<0.05); NlocB= Number of pigs of Local(Indigenous) breed in the \\
herd; NKrgB= Number of pigs of Korhogo breed in the herd; NLwB= Number of pigs of Large white breed in the herd; \\
Krg= Korhogo; Loc= Local or Indigenous; Mgl= Mongrel; Lw= Large white.
\end{tabular}




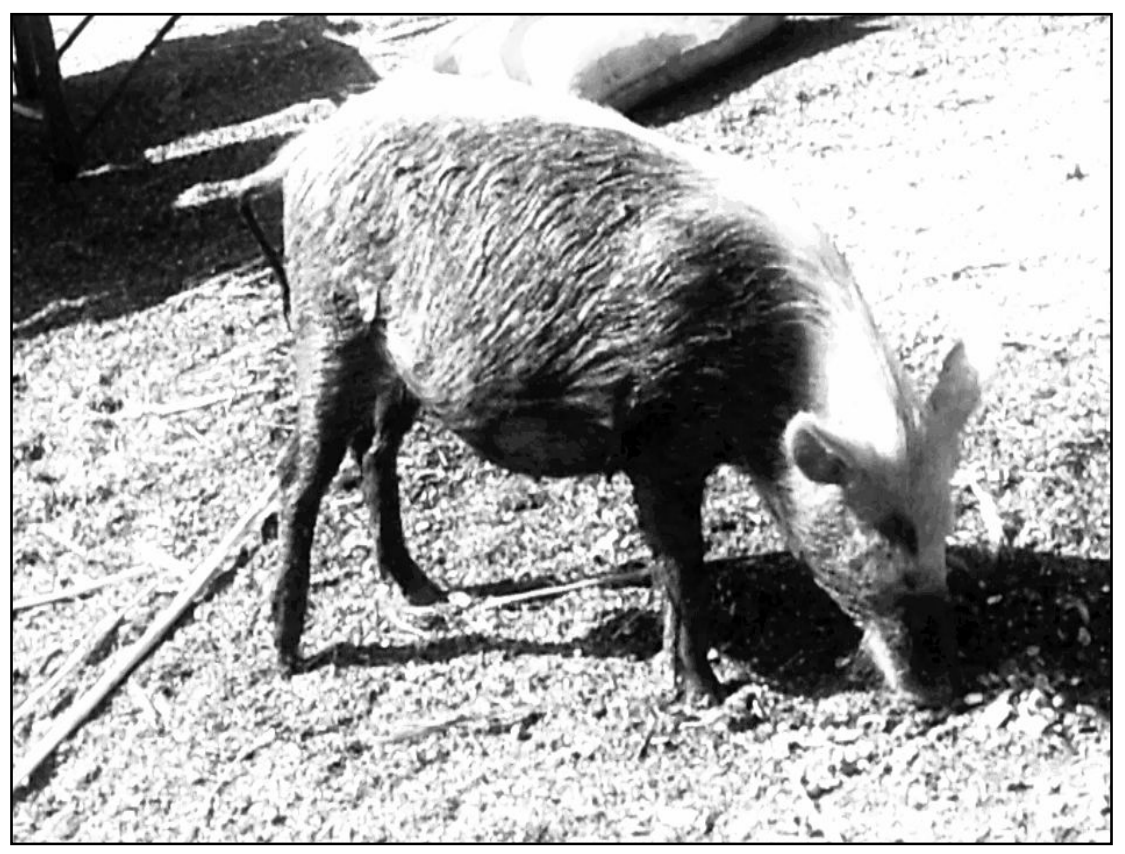

Figure 1: Pig of local breed of gray color.

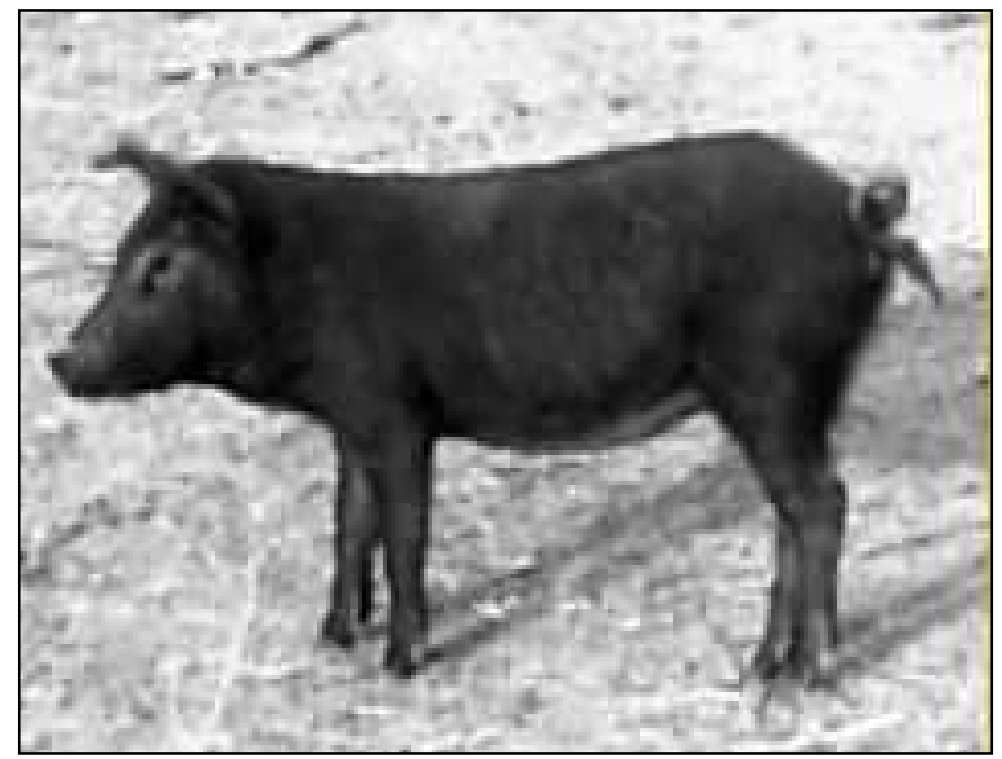

Figure 2: Pig of local breed of black color. 
T. KIENDREBEOGO et al. / Int. J. Biol. Chem. Sci. 6(4): 1535-1547, 2012
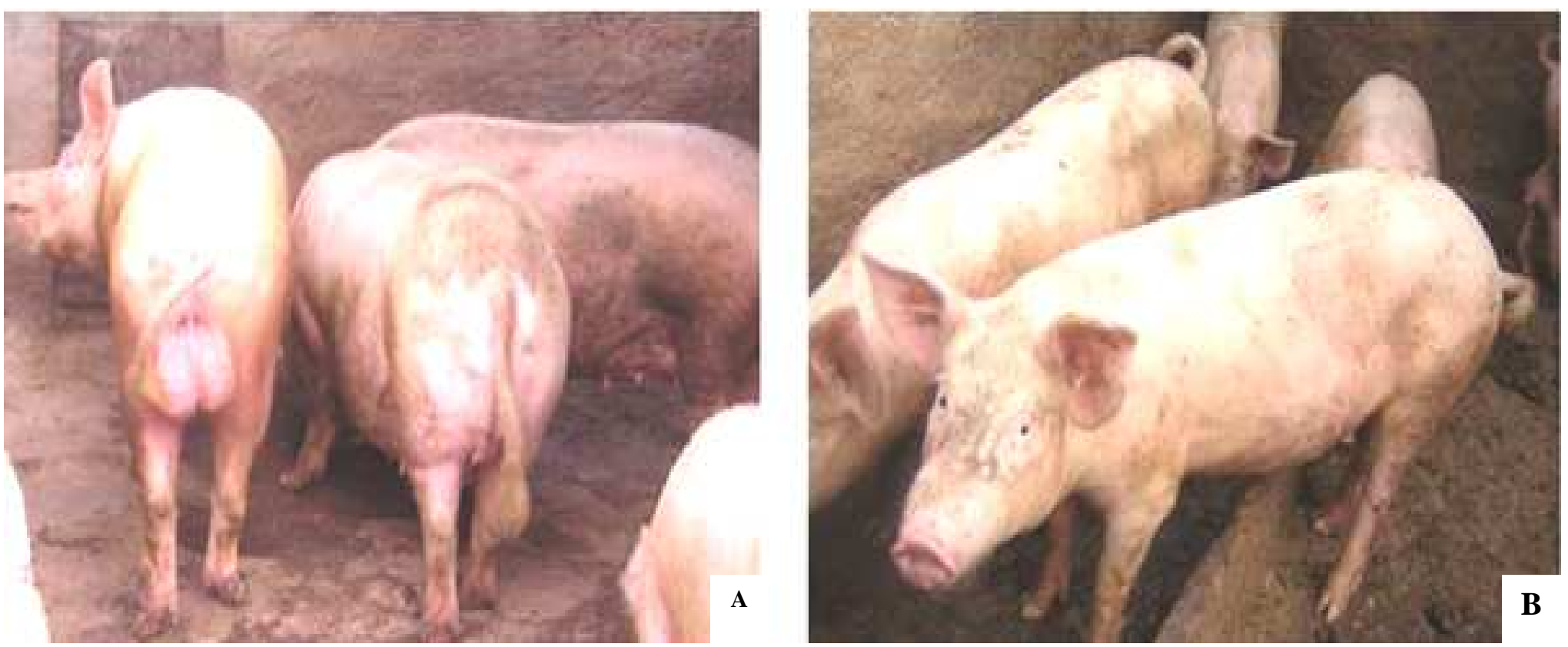

Figure3: Korhogo breed pigs placed in boxes for coupling (A) and the fattening (B). 


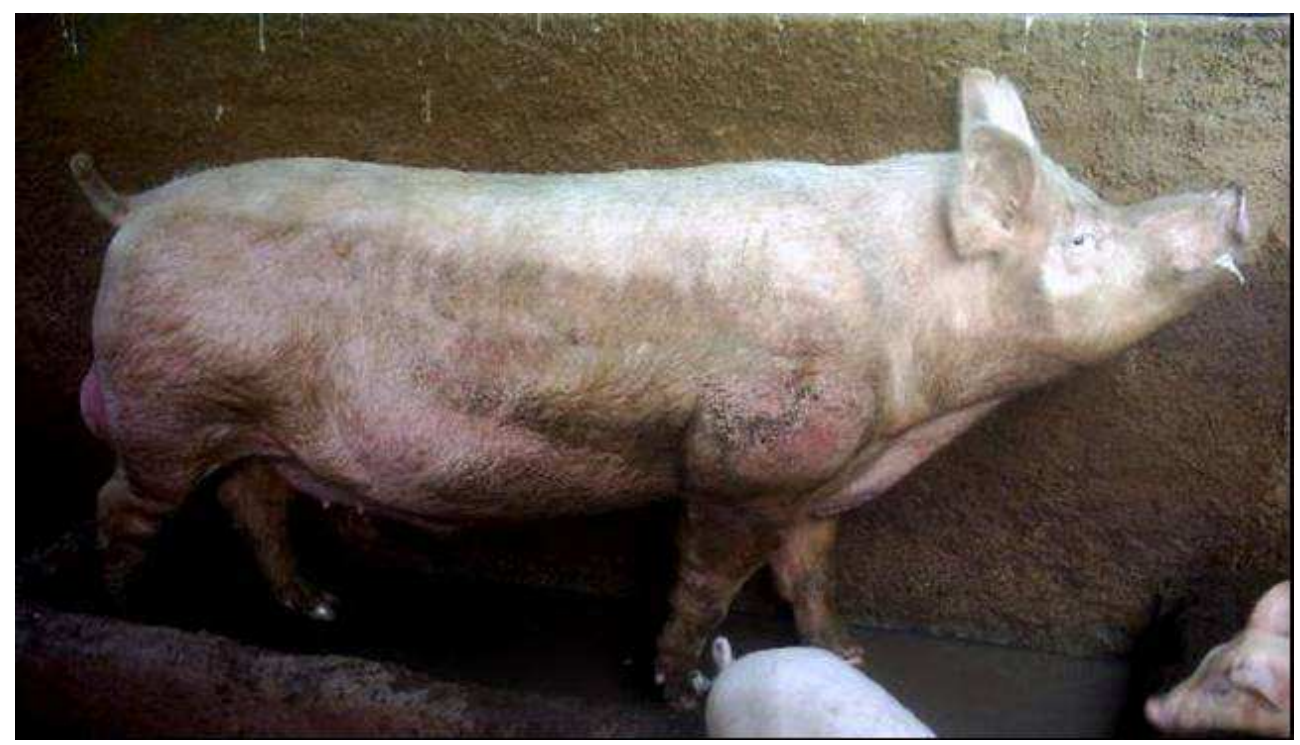

Figure 4: Pig of Large White breed.

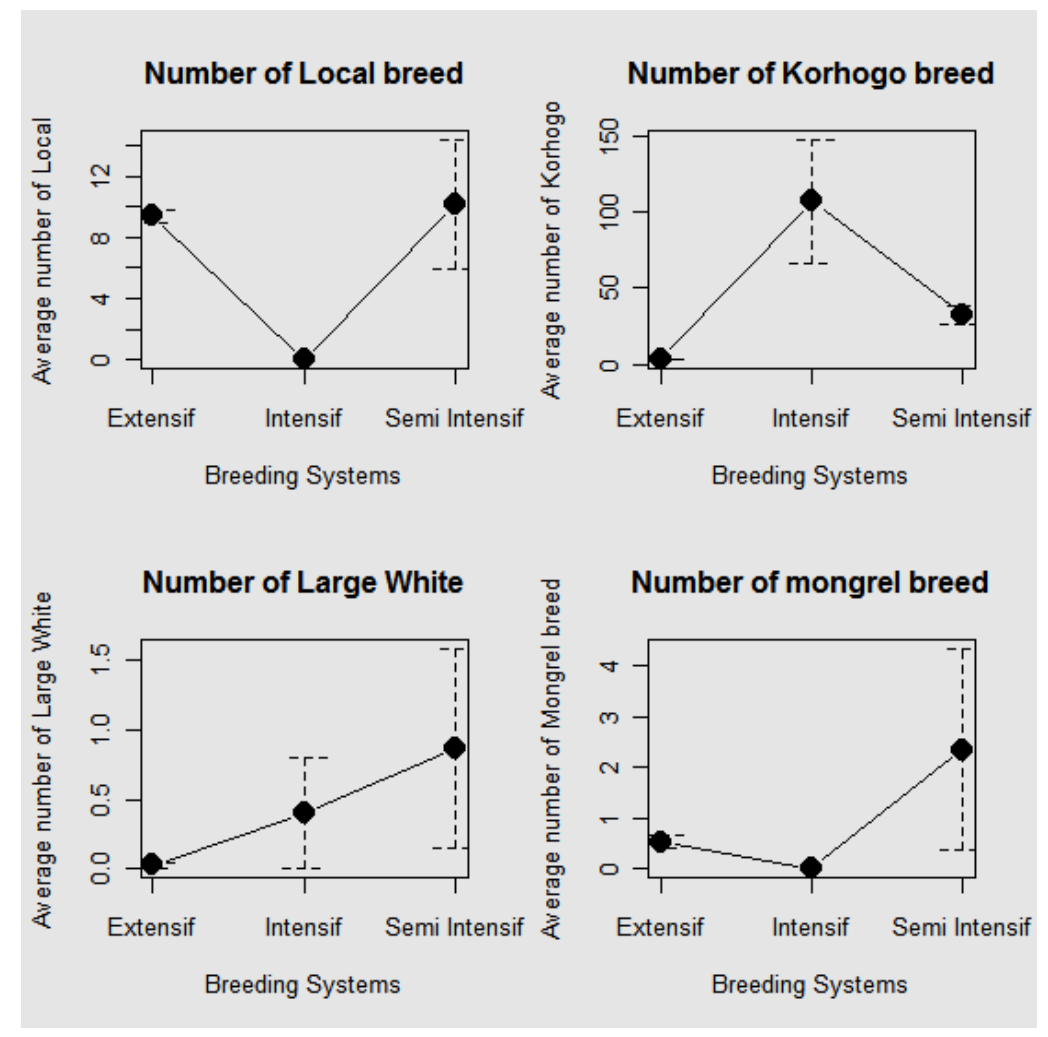

Figure 5: Average number of pig heads according to the breed and the system of breeding. 


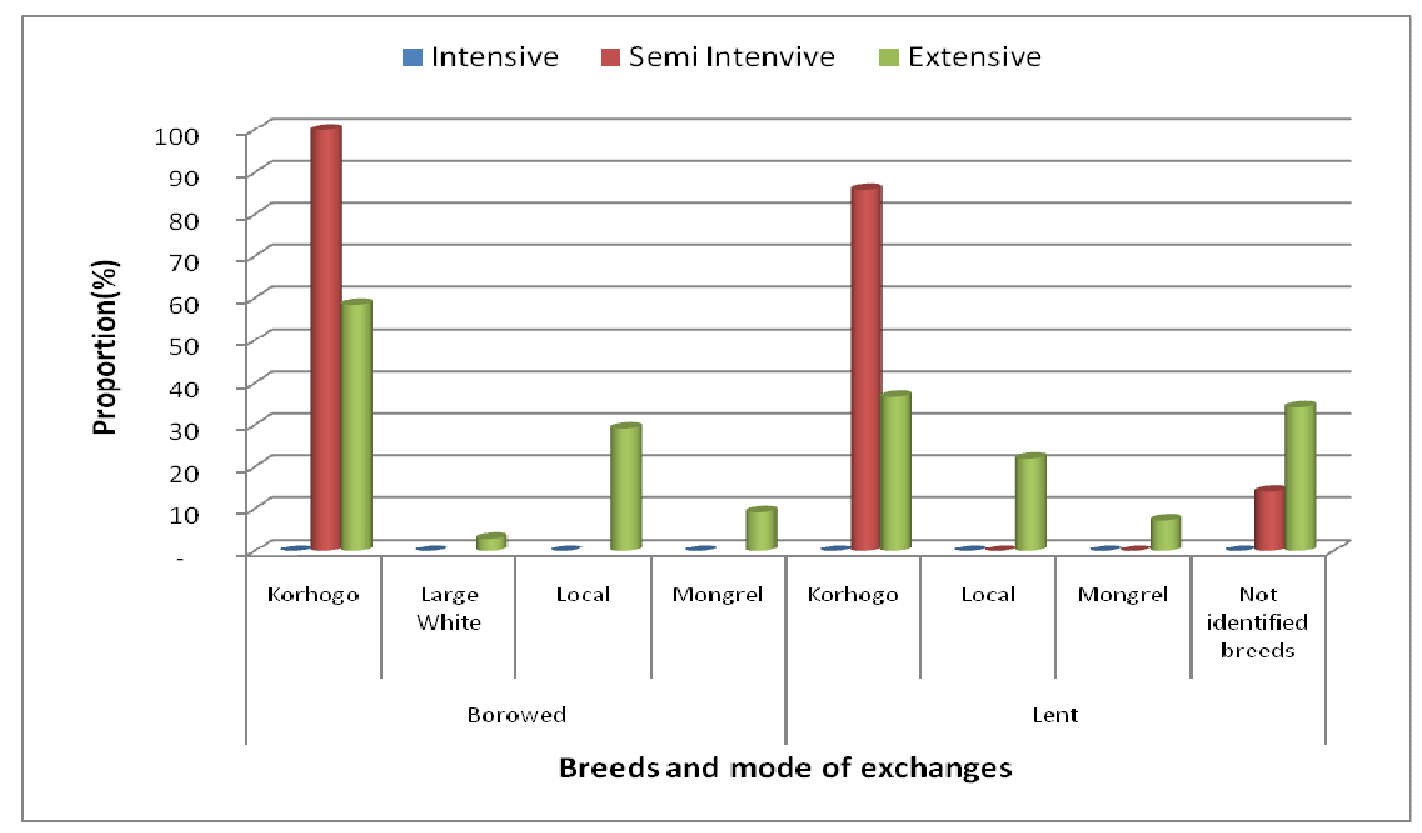

Figure 6: Proportion of pig implied in the loans and of boar between producers.

\section{DISCUSSION}

Our results show the presence of 3 breeds: the Korhogo, the Large White, and the Local (Indigenous breed) and the Mongrel pigs in Bobo-Dioulasso's area. These listed breeds of pig are in general those met in Burkina Faso (Abou, 1985; Kaboré, 1996; MRA, 2003). The Large White created in England is an international breed today. The European pure breed is most known of the stockbreeders of Burkina Faso. It is recognized by its large size, the big length of its body reaching $2 \mathrm{~m}$ for the male and $1,85 \mathrm{~m}$ for the female (Paré, 2004). Its members are strong and it has a good mobility. It has a large and strong head, sharp eyes, a large snout, and some triangular large well-raised ears. It presents a good adaptation to the high temperatures (MRA, 2003). Korhogo breed (Pig of Korhogo) is described as a product of craonnais' breed, crossed with indigenous females. The best descendants of this crossing would then have been coupled with boars of Yorkshire (Large White). The stabilization of this step into the village of Korhogo in Republic of Côte-D'ivoire gave the breed called Korhogo (CIRAD, 2009). It is known as a rustic and prolific breed, present into all of pig's breeding systems of Bobo-Dioulasso's area. If these improved breeds said exotic breeds have some ethnological well-known characteristics, it is not the same for the indigenous one. In many countries of Africa, the pig breeds are not inventoried and well defined as breed. They're regarded as, "Indigenous or Local", or "none improved" pig's breeds. This point of view is shared by Ayalew et al. (2011) who said that the taxonomy and the diversity of the indigenous pigs of Papua New Guinea are not wellknown. However, the indigenous breed is a pig of small size, rustic of dress white, black or mapie and white with silks very hard, of great heterogeneity of productivity (Figures 1 and 2). The weight of adult pigs, still alive, is variable between 40 and 60kg (Holnes, 1994). In this order of idea, Nianogo et al. (1996) have reported a weak meat productivity of $87.8 \mathrm{G}$ and $304 \mathrm{G}$ daily average weight gain (GMQ) respectively in the traditional and modern exploitations. However, in Burkina Faso, 2 majors varieties of the indigenous 
breeds are described (Nianogo et al., 1996): The first variety is known as having a small size, with short legs, well-raised ears, not very prolific (5-6 small by range); the second variety is known as having big size, light, with long and fine legs, well-raised ears, very prolific (10-15 piglets by range). Of these two major varieties and compared to phenotypical description and with the known average weights indicated for the Indigenous breed met in the zone (Figure 1 and 2) it could be identified with the first two varieties. However, many hazardous crossings make necessary a better characterization of pig's breeds in Bobo-Dioulasso's area. This will help to have a good base of management of pig genetic resources. In addition, our results show the greatest representativeness of the Indigenous breed (61\% of the pigs) in urban and suburban zone of Bobo-Dioulasso. These results are in agreement with Kaboré (1996), who reported that in the zone of Ouagadougou the local breed represented more than $60 \%$ and is more represented in Burkina Faso. If we stick to the $39 \%$ of the proportion of improved breeds (Large White and Korhogo) of our results, their representativeness is higher in the zone of Bobo-Dioulasso than the $10-20 \%$ of the pig population in a certain number of countries of Westerner Africa (CIRAD, 2009). In the opposite direction, others authors (Abou, 1985; CIRAD, 2009), showed that the mongrel breeds (87.97\%) were more represented compared to the Indigenous breed (10-20\%) and imported pigs' breeds $(5.04 \%)$. In the zone of Ouagadougou (Burkina Faso), the results of a survey showed that $43.7 \%$ of stockbreeders have mongrel breed, $35.9 \%$ the local breed, and $10.7 \%$ have the mongrel and the indigenous breed. Others, (9.7\%), have the mongrel and the imported breeds (Kaboré, 1996). This apparent contradiction is undoubtedly the result of the hazardous crossings, which do not obey to any program of genetic improvement, running then a risk of a genetic diversity. The total importance noticed of the local breed in the stockbreeders can be justified by the request largely directed towards the meat of the local breed (Figure 6) and the greatest representativeness of the traditional extensive breeding system. Indeed, this last system delays on the adoption of new technologies, among which the introduction of the improved breeds into the herd. With the scale of the systems, exotic breeds (Large White and Korhogo) are more present in the intensive and semi-intensive systems (Figure 5). Regarded as improved systems, this result is in agreement with CIRAD (2009) who affirms that the breeds, which are founded there are always mongrel breeds. If that is probable for the Korhogo breed that is not true for the Large White, which has been introduce into the zone a few years ago. The results relating to the size of the litters (TP) for the local breed in the semi-intensive system $(6 \pm 1$ piglets) are in agreement with those of Nianogo et al. (1996) which gave 5-6 piglets per litter for the variety of small size. In the extensive system, this difference increases of a piglet ( $7 \pm 2$ piglets). This difference could be explained by the mode of guarding in the traditional system (freedom), which is less restricting and is better appropriated for the indigenous breed. These litter values are very close to those given for the local breed to Benin (7.3 piglets), to Nigeria (6.7 piglets) and to Cameroon (7.8 piglets) (CIRAD, 2009). However, this breed has a higher fruitfulness (2-2.4 ranges/year) with the mortalities less marked of $6 \%$ (before and after weaning) in the semi-intensive system, compared to extensive system where it is less fruitfulness (1.5 to 2 ranges/year) and is, sometimes, coupled to a high rate of mortality (Table 2). This fruitfulness is close to what is reported by the CIRAD (2009) (1.2 -1.8 ranges/year). High rate of mortality (18\%) before weaning in the semi-intensive system are lower than the rate of mortality of $19.1 \%$ and 22\% respectively in Benin and Cameroon and higher than the $15.1 \%$ for Nigeria (CIRAD, 2009). Improved pig's breeds (Korhogo, Large White and mongrel breed) compared to the indigenous breed, show their 
supremacy for the number of piglets per litter (TP) in all systems. The TP of Large White in the intensive system (10 \pm 2 piglets) agree well with the averages of 12.5 piglets for the origin country and 12 piglets (Paré, 2004) in the scattering station of Banakélédaga in the zone of Bobo-Dioulasso. The TP in the semiintensive system $(9 \pm 2$ piglets $)$ practically correspond to the TP given to Senegal (9.31 piglets); to Nigeria (8.02); to Togo (8.39) and to Guadeloupe (9.43 piglets) (Ayssiwede, 2005). In Madagascar (9 piglets), Centre Africa Republic (9.6 piglets), the rate of mortality before weaning of this breed in the intensive $(17 \%)$ and the semi-intensive $(15 \%)$ systems are quite as high as those of some countries (Nigeria, 17.5\%; Madagascar, $15.5 \%)$, higher than in other countries as Senegal (12.9\%), RCA (10.2\%) and Togo (7.74\%) (Ayssiwede, 2005). More significant mortalities were quoted for Senegal $(23.4 \%)$ and Guadeloupe $(21.1 \%)$. These data are found above. These elements indicate the efforts made for Large White breeding in some countries, which are in the process of development, although it is internationally recognized. It is however observed weaker TP in the extensive system for the Korhogo breed and semi-intensive for the Large White with high mortality, before weaning, in the systems semi-intensive and extensive. This is quite normal because these pig's breeds are more demanding. If the parameters above are determinant for the productivity of the pigs, their good growth weight interests much the stockbreeders of the zone. Indeed, for all pig's breeds in all systems, the objective in the long term of the producers is to sell especially adult pigs. Moreover, the weight to the sale of the pigs determines the access to a permanent (pork-butchery and export), remunerative (400 with $550 \mathrm{FCFA} / \mathrm{kg}$ of live weight) or nonremunerative market (300-350 FCFA/kg of live Weight) (Kiendrébéogo et al., 2008). The research of the improvement of pig and farms productivity was certainly at the base of many exchanges of boars between farms, with a greater implication of Korhogo breed
(Figure3). The CIRAD (2009), quoting Meyer (personal communication), indicates that Korhogo breed has known an undeniable success. Because of good productivity, this breed has been largely exported to others bordering countries as Burkina Faso. It should be noted that the exchanges are done without a genetic management program. This insufficiency can generate consanguinity problems, whose consequences are, among other things, the appearance of congenital pathologies and the absorption of breeds slightly represented, and can cause the loss of genetic diversity. We can understand the significant differences in weight of the pigs sold according to systems' of breeding. For this reason, the role played by the breed, among other factors, in the formation of the weights in breeding system and herd of several breeds was significant. Indeed, as results of variance analysis show (Tables 5), the weight of the sold adult pigs was influenced by the racial composition of the herd and the interaction between the breeds. It is the case in the extensive system where the dominant local breed in the herds $(72.96 \%)$ could contribute, to maintain the levels of weight around $70 \mathrm{~kg}(60 \pm 33 \mathrm{~kg})$. In the opposite direction to that, the Korhogo and Large White breeds, which are more significant $(72.28 \%)$ in the semi-intensive system, contributed to raise the average weights, which tend to $100 \mathrm{~kg}$. However, we must recognize that the weights of Large White and Korhogo, are largely below the awaited weight of Large White (180-220 kg) (Paré, 2004) and of Korhogo breeds.

\section{Conclusion}

The study allowed tomake an inventory of three principal pig's breeds (Local or Indigenous, Korhogo and Large White) and of the mongrel breeds in the urban and suburban zone of Bobo-Dioulasso. It showed that in the current systems of breeding and the pig mortality, the indigenous breed is not only required but also most representative. However, It remains that the results are based 
on the declarations of the stockbreeders and the observations of the investigators, which remain insufficient to claim without any doubt that the inventory of the races was exhaustive. The study also showed that the improved breeds (Large White, Korhogo and Mongrel breeds) are more present in intensified systems (intensive and semi-intensive), contrary to the more significant indigenous breed in the extensive system. This aspect testifies of the research of the improvement of the pig breeding productivity. However, many exchanges of boar without genetic improvement program are carrying risk of the genetic diversity loss and congenital diseases being causing some significant losses in the pig breeding. It becomes also urgent to organize reproduction and boar exchanges from farm to farm, in order to preserve racial diversity and the intrinsic productivity of each breed. The emergency of the diversification of the products (production of piglets, production of pigs of butchery) is a pressing need that must limit to the maximum these exchanges. Actions tending to improve knowledge of the Indigenous pig, its breeding in rural area to support its conservation are strongly encouraged. Finally, the choice of breeds to be raised and the constitution of mono breed's herds should limit considerably the negative influence of the interactions between breeds, especially, on pig's weight productivity. It showed that, at the current state systems of breeding and taking into account the mortality in the zone, the local breed is not only required but most representative. It remains, however, that the results are based on the declarations of the stockbreeders and the observations of the investigators, which remain insufficient to affirm without any doubt that the inventory of the breeds is exhaustive. The study also showed that the improved breeds (Large White Korhogo and Mongrel breed) are more presents in the intensified systems (intensive and semiintensive) contrary to the more significant local breed in the extensive system. This testifies the research of the improvement of the breeding productivity. However, many exchanges of boar in the absence of a diagram of genetic improvement carried some risks of genetic diversity loss and included some congenital diseases being able to cause significant losses for the breeding. It is also urgent for the zone and the country to organize the reproduction in order to preserve racial diversity and the intrinsic performances of each breed. The diversification of the products (production of sires, production of pigs of butchery) is a pressing need to limit these exchanges, which in addition to the mentioned known risks constitute from a breeding to another. Actions tending to improve knowledge of the local breed, its rural breeding especially in order to support its conservation are quickly to be encouraged. Lastly, the choice of breeds to be raised and the constitution of mono breed's herds would help to limit considerably the negative influence of the interactions between breeds, especially on pig's weight productivity.

\section{REFERENCES}

Abou K. 1985. Situation actuelle de l'élevage porcin dans la Province du Kadiogo et possibilités d'amélioration. Mémoire d'Ingénieur du développement Rural option élevage. Université de Ouagadougou, Institut Supérieur Polytechnique (ISP), 67p.

Ayalew W, Danbaro G, Dom M, Amben S, Besari F, Moran C, Nidup K. 2011. Genetic and cultural significance of indigenous pigs in Papua New Guinea and their phenotypic haracteristics. In Animal Genetic Resources. Food and Agriculture Organization of the United Nations: USA.

Ayssiwede SB. 2005. L'Insémination Artificielle Porcine : une perspective pour l'amélioration de la productivité des porcs au Bénin. Mémoire d'étude spécialisée en gestion des ressources animales et végétales en milieux tropicaux (DESGRAVMT), Filière Productions Animales. Université de Liège (ULLG), 
Faculté Universitaire des Sciences Agronomiques.

CIRAD (Centre de coopération internationale en recherche agronomique pour le développement). 2009. Les populations porcines en Afrique de l'Ouest, l'histoire, les origines, les races locales et les principales caractéristiques de l'élevage en Afrique. http://pigtrop.cirad.fr/content/ pdf/4985 (21/04/2009).

Drabo A. 2007. Contraintes actuelles et perspectives de l'élevage porcin dans les zones intra et péri urbaines de Ouagadougou au Burkina Faso. Mémoire d'Ingénieur Zootechnicien, Université du Mali, Bamako, 68p.

Holnes H. 1994. 28 Le Porc. Manuel le Technicien d'Agriculture. Editions Maisonneuve et Larose: Paris 221.

Kaboré N. 1996. Influence de ressources alimentaires locales sur l'évolution pondérale des porcs locaux à l'engrais au Burkina Faso. Mémoire de MSc. en Production Animale à l'Institut de Médecine Tropicale Prince Léopold, Antwerpen, Belgique, 85p.

Kiendrébéogo T, Hamadou S, Mopaté LY, KABOREZOUNGRANA CY. 2008. Typologie des élevages porcins urbains et périurbains de Bobo -Dioulasso (Burkina Faso). Revue Africaine de Santé et de Production Animale, 6(3-4): 2008.

Lebret B, Barthélémy S, Bonhomme N, Prunier A, Dourmad JY. 2008. Variation de la qualité de la viande de porc selon la race et le système d'élevage: dispositif de recherche de marqueur. http://www.officeelevage.fr/vpc/12jsmtv/12emes_JSMTV.pd $f, 149-150$.

MED, MRA. 2004. Deuxième Enquête Nationale sur les Effectifs du Cheptel (ENECII). Résultats et Analyses (Tome II). MED, MRA: Ouagadougou, Burkina Faso, 85p.

MEF. 2008. Recensement général de la population et de l'habitat de 2006 : résultats définitifs. Rapport portant sur le recensement général de la population du Burkina Faso en 2006, 56p.

MRA. 2003. Diagnostique de la filière porcine au Burkina Faso. Rapport d'étude dans le cadre de la mise en ouvre du plan d'actions et programmes d'investissements du secteur de l'élevage (PAPISE), Version finale, 78p.

Nianogo AJ, Sanfo R, Kondombo D, Neya SB. 1996. Le point sur les ressources génétiques en matière d'élevage au Burkina Faso. AGRI 17 Animal Genetic Ressources Information. ftp://ftp.fao.org/ docrep/fao/012/v9701t/v9701t01.pdf (21/06/2012).

Paré S. 2004. Le porc Large White. Document informatif sur les performances comparées du porc Large White selon son milieu d'origine et en station de diffusion de l'Antenne Régional du Centre National d'Elevage et d'Amélioration Génétique de Bobo-Dioulasso, 5p. 